\title{
EFFICACY OF MODIFIED CORTICOTOMY TECHNIQUE COMBINED WITH SKELETAL ANCHORAGE IN MAXILLARY DENTOALVEOLAR CLASS II MALOCCLUSION CORRECTION
}

\author{
Abdel Aziz Baiomy Abdullah Baiomy* and Wessam El-Din Raafat Ali Gouda**
}

\begin{abstract}
Aim: It was to evaluate efficacy of modified corticotomy technique (combination between vertical and perforation corticotomy) versus standard vertical corticotomy technique in canine retraction for maxillary dentoalveolar class II malocclusion correction when they were in combination with skeletal anchorage.

Patients and methods: 24 patients had maxillary class II malocclusion were treated by skeletal anchorage application combined by corticotomy cuts in one side and alone in another side (control side). Groups were divided randomly into equal groups according corticotomy techniques \{group I: vertical corticotomy, group II: vertical and perforation corticotomy (modified corticotomy)\}. The upper arch was immediately activated bilaterally after surgical procedure for retraction of the maxillary canines. The patients were followed for 6 months. Statistical analysis was done for the duration of canine retraction, rate of canine retraction, molar anchorage loss, gingival probing depth, and canine root resorption parameters.
\end{abstract}

Results : The control side took significant longer duration than the corticotomy side in all groups. Group I showed statistically significant longer duration for canine movement than groups II .Molar anchorage loss parameter during canine retraction was unsignificant in both groups. Other parameters showed no significant differences between both sides in groups.

Conclusion: Modified corticotomy technique is an effective way to accelerate orthodontic tooth movement, with superiority for it than vertical corticotomy in this aspect.

KEYWORDS: Corticotomy technique, canine retraction, skeletal anchorage, miniscrew implants

\footnotetext{
* Assistant Professor of Oral \& Maxillofacial Surgery, Faculty of Dental Medicine, Al-Azhar University, (Assiut, Boys)
}

** Lecturer of Orthodontics, Faculty of Dental Medicine, Al-Azhar University, (Assiut, Boys). Egypt 


\section{INTRODUCTION}

Several surgical interventions have been joined with ordinary orthodontics for improved and shortening time of treatment. Corticotomy was acquainted as a surgical procedure with abbreviate therapy time. Corticotomy eliminates the cortical bone that emphatically opposes orthodontic force inside jaw and keeps the bone marrow unresolved issue blood dissemination and congruity of bone tissues to downsize danger of necrosis and encourage tooth movement ${ }^{(1)}$.

A corticotomy is characterized as a surgery whereby just the cortical bone is cut, punctured, or precisely adjusted through both the buccal and/ or lingual cortical plates that encompass the tooth, only through the medullary bone ${ }^{(2)}$.

Corticotomies can be applied to facilitate orthodontic treatment in several cases, such as retraction of the anterior teeth for bimaxillary dentoalveolar protrusion combined by skeletal anchorage ${ }^{(3,4)}$ intrusion of overerrupted molars with magnets ${ }^{(4)}$ or miniplates, ${ }^{(5)}$ molar distalization to correct class II malocclusion, ${ }^{(5,6)}$ closing of anterior open bite ${ }^{(7,8)}$ and correction of cross bites, ${ }^{(9,10)}$ and maxillary or mandibular posterior displacement of anterior alveolar segment. ${ }^{(11,12)}$

The design of the corticotomy cuts and perforations is by all accounts superfluous, yet it appears to be clear they should puncture the cortical layer of bone and broaden just into the shallow part of the medullary bone. Therefore, sufficient determination of corticotomy configuration is fundamental to diminished treatment time with not many complications and low morbidity . ${ }^{(13)}$

With respect to dangers of corticotomy methodology, for example, periodontal harm and devitalization of the teeth and bony sections on account of deficient blood gracefully, original alveolar corticotomy procedure has been adjusted throughout the long term to produce faster tooth movement and eliminate its possible risks. ${ }^{(2,14)}$
In the same context, miniscrews were presented as absolute anchorage devices in orthodontic treatment leading to decrease time of treatment. Astounding treatment results have been accounted for utilizing miniscrews for orthodontic anchorage inseveral sorts of malocclusion, since they flexibly stable anchorage for various tooth movements, including intrusion, extrusion, distalization, protraction, midline coordination and changes in the occlusal plane.

Accordingly, the current study was atrial to evaluate efficacy of modified corticotomy technique (combination between vertical and perforation corticotomy) in production faster tooth movement leading to less duration of orthodontic treatment using mini screw implant as an maximum anchorage to avoid anchorage loss during canine retraction.

\section{PATIENTS AND METHODS:}

This controlled randomized split design study was carried out upon 24 patients (16 females and 8 males) with an age range from 14 to 22 years (mean $=18$ years), selected from the outpatient orthodontic clinic, Faculty of Dental medicine, Al-Azhar University, Assiut branch.Clinical study was extended for 3 years (from October 2018 till November 2020) . Informed consent was obtained from all patients before any study procedures were performed. The study was conducted according to rules of ethics declared by Helsinki, and ethical committee approval was obtained from Al-Azhar ethical committee.

\section{Selection criteria:}

- Inclusion criteria: Patient with class II deviation I malocclusion without any previous orthodontic treatment.

- Exclusion criteria: Patients having alveolar bone resorption, periodontal diseasesand patients were prescribed regular doses of nonsteroidal anti-inflammatory drugs or any drugs interfere 
with the rate of orthodontic tooth movement were excluded.

- Patients grouping : The patients were divided randomly into two equal groups using online software (https://www.randomizer.org) according to type of alveolar corticotomy techniques (Group I: corticotomy grooves,and Group II: combination corticotomy ).

\section{Preoperative assessment}

Preoperative strategies included history taking, intraoral and extraoral clinical assessment, quiet photos from different perspectives, and study cast. After clinical examination, a complete radiological assessment was carried out including periapical radiographs to guide the implantation of the miniscrew before and after insertion to check its proper position. Orthopantomic, and lateral cephalometric radiographs in centric occlusion were made for skeletal and dental analysis (Fig.1 A\&B) .

\section{Operative procedures:}

All orthodontic procedures were done in the orthodontic clinic, Faculty of Dental medicine, Al-Azhar University, Assiut branch while surgical procedures were carried out in minor surgical operation room of oral and maxillofacial department, Faculty of Dental medicine,Al-Azhar University, Assiut branch. Operative procedures were carried out as the following:

- After leveling and alignment phase of treatment, miniscrews $(1.6 \mathrm{~mm}$ in diameter and $9 \mathrm{~mm}$ in length) (Orthopro. Rock orthodontic mini implant, USA) were placed bilaterally between maxillary second premolar and maxillary first molar as skeletal anchorage.(Fig.1 B\&C).
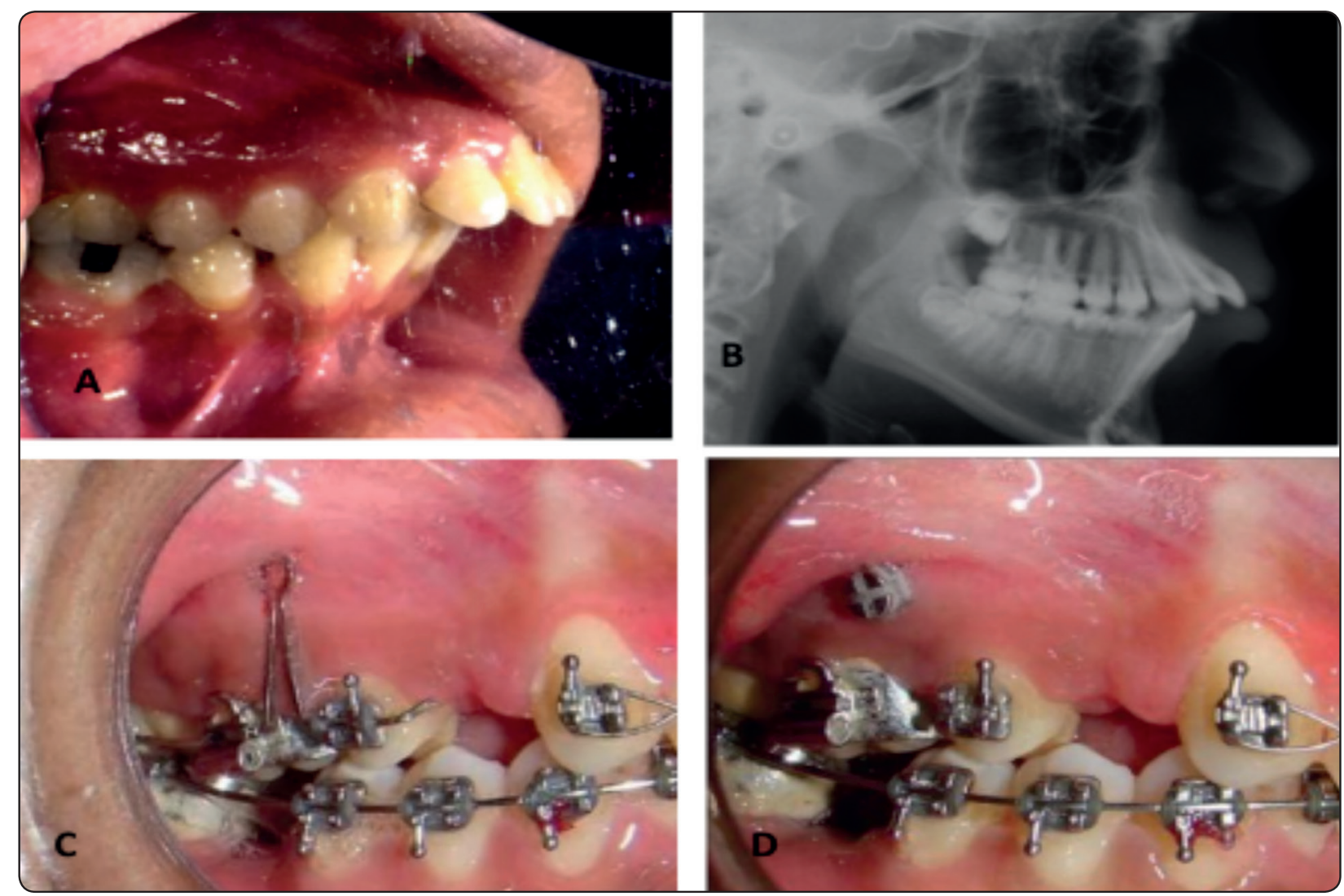

Fig. (1) (A) Preoperative intra oral photographs, (B) Preoperative lateral cephalometric x-ray, (C) Rectangular wire in the form of $\mathrm{L}$ - shape with end eyelet to locate the appropriate position for insertion of mini screw, (D) Miniscrews after insertion 
- Before corticotomy procedures, first premolars were extracted and each patient was received prophylactic antibiotic, mouth wash, and antiinflammatory drugs to decrease rate of incidence of infection and edema after corticotomy procedures.

- After injection of local anesthesia at the side of operation a semi-lunar mucoperiosteal flap was elevated as possible beyond the root apex of the canine (Fig.2A).

- In all corticotomy procedures a number 2 round bur was utilized in a low-speed hand piece under overflowing saline water system, extending from the maxillary lateral incisor to the maxillary first premolar area and the opposite side was left as control. The depth of the holes grooves approximated the width of the buccal cortical bone. Thereafter, the flap was carefully repositioned and sutured with black silk 4-0 black silk by utilizing interrupted technique (Fig.2 B\&C).

- Two weeks after the implantation procedure, the patients were recalled for initiation of orthodontic mechanics, using nickel-titanium closed-coil springs applying $150 \mathrm{~g}$ on each side were used for canine retraction .(Fig.2D).

\section{Postoperative care and follow-up:}

\section{Postoperative care:}

All patients in groups were instructed to apply ice-packs over cheek area for 20 min every hour for $6 \mathrm{~h}$ postoperatively,keep on a soft diet for the first 48 hours, and rinse their mouth with chlorhexidine mouth wash (DG-wash,AlEsraa Pharmaceuticals,
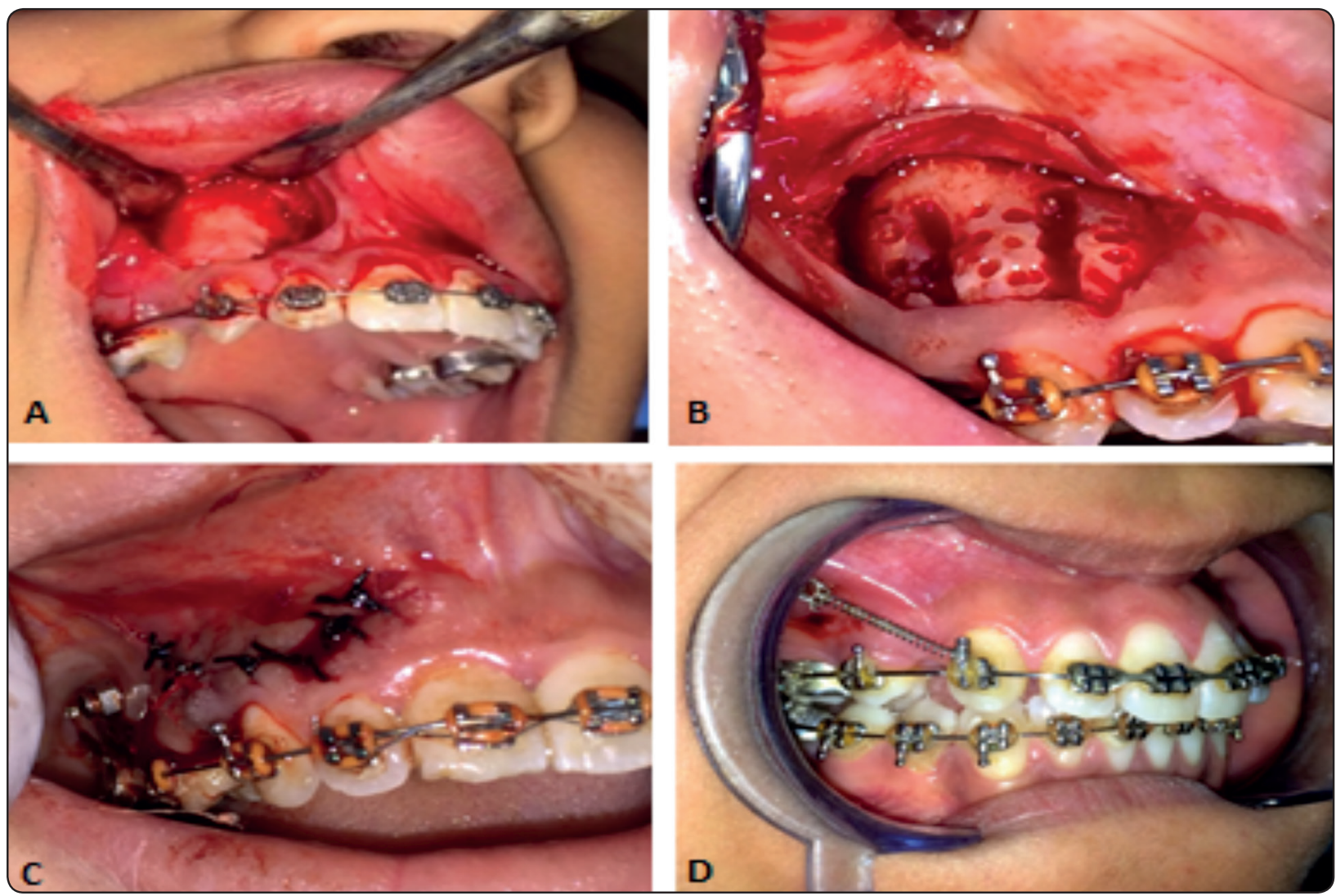

Fig. 2: (A) Semi-lunar mucoperiosteal flap (B) combination corticotomy (C) Wound closure (D) Canine retraction by nickeltitanium closed-coil 
Fourth Industrial Zone, Badr Industrial City, Cairo, Egypt.) starting on the second day after surgery, three times per day during the first week postoperative. Amoxicillin $875 \mathrm{mg} /$ claviulanic acid $125 \mathrm{mg}$ antibiotic tablet (Augmentin $1 \mathrm{gm}$, Glaxosmithkline, Australia) was prescribed as one tablet every 12 hours for seven days postoperatively. Diclofenac sodium non-steroidal anti-inflammatory drugs $75 \mathrm{mg}$ tabs (Cataflam, Novartis pharma, Basel, Switzerland) was prescribed to be used one tablet every 8 hours for seven days. Chymotrypsin + trypsin ${ }^{\circledR}$ tablets (Alphintern, Kahira. pharm \& chem. Ind. co., Cairo, Egypt), was administrated half an hour before meals 3 times for seven days. Sutures were removed after 10 days.

\section{Postoperative assessment:}

Postoperative clinical and radiographic evaluation was performed at end 1,2, and 3 months. Clinical examination included wound examination for suture breakdown, or dehiscence, pain, and assessment of duration of canine retraction, molar anchorage loss, and gingival probing depth. Dental casts were taken during canine retraction for evaluation of the rate of canine retraction. Orthopanoramic radiographs were taken for all patients after canine retraction.

\section{Statistical analysis:}

The data were collected, tabulated and statistically analysed by Statistical Package for Social Sciences (SPSS) version 25. Descriptive statistics and frequency distribution were analysed. Intergroup comparison was done using an unpaired $t$ test. A paired $t$ test was used for comparison inside groups. $\mathrm{P}<0.05$ was considered statistically significant, and $\mathrm{P}<0.001$ was considered highly significant.

\section{RESULTS}

All patients tolerated surgical procedures with slight to mild pain sensation at surgical site for one to three days duration after surgical procedures. There was no significant difference between both groups at all intervals of the study. Where, all patients showed excellent soft tissue healing, and fully keratinized mucosa without any signs of inflammation, or dehiscence. The clinical mobility test for miniscrow mobility revealed failure of four miniscrews implant. They were removed and reinserted after healing of the inflammation.

The outcomes in this study have shown that it is conceivable to quickly canine retraction utilizingcorticotomy-facilitated orthodontics and skeletal anchorage. Retraction of canineswas significantly higher $(\mathrm{P} \leq 0.01)$ on the operated side than on the control side in all groups during the 1st, and 2nd months intervals. After the corticotomy procedure by two months, the average monthly rate of canine retraction was significantly higher $(\mathrm{P} \leq 0.01)$ approximately 1.8 times faster on the corticotomy side contrasted with the control side in all groups. Corticotomy side in group I showed highly statistically significant longer duration than groups II although it showed statistically significant shorter duration than the control side.

Molar anchorage loss $(\mathrm{P}>0.05)$ was unsignificant during canine retraction on either the corticotomy or the control side. There was no statistically significant difference between changes in anchorage loss in different groups and the control.

In this study the assessment of probing depths, gingival index, and canine apical root resorption showed no significant differences between the study and control sides before and after canine retraction in all patients. 


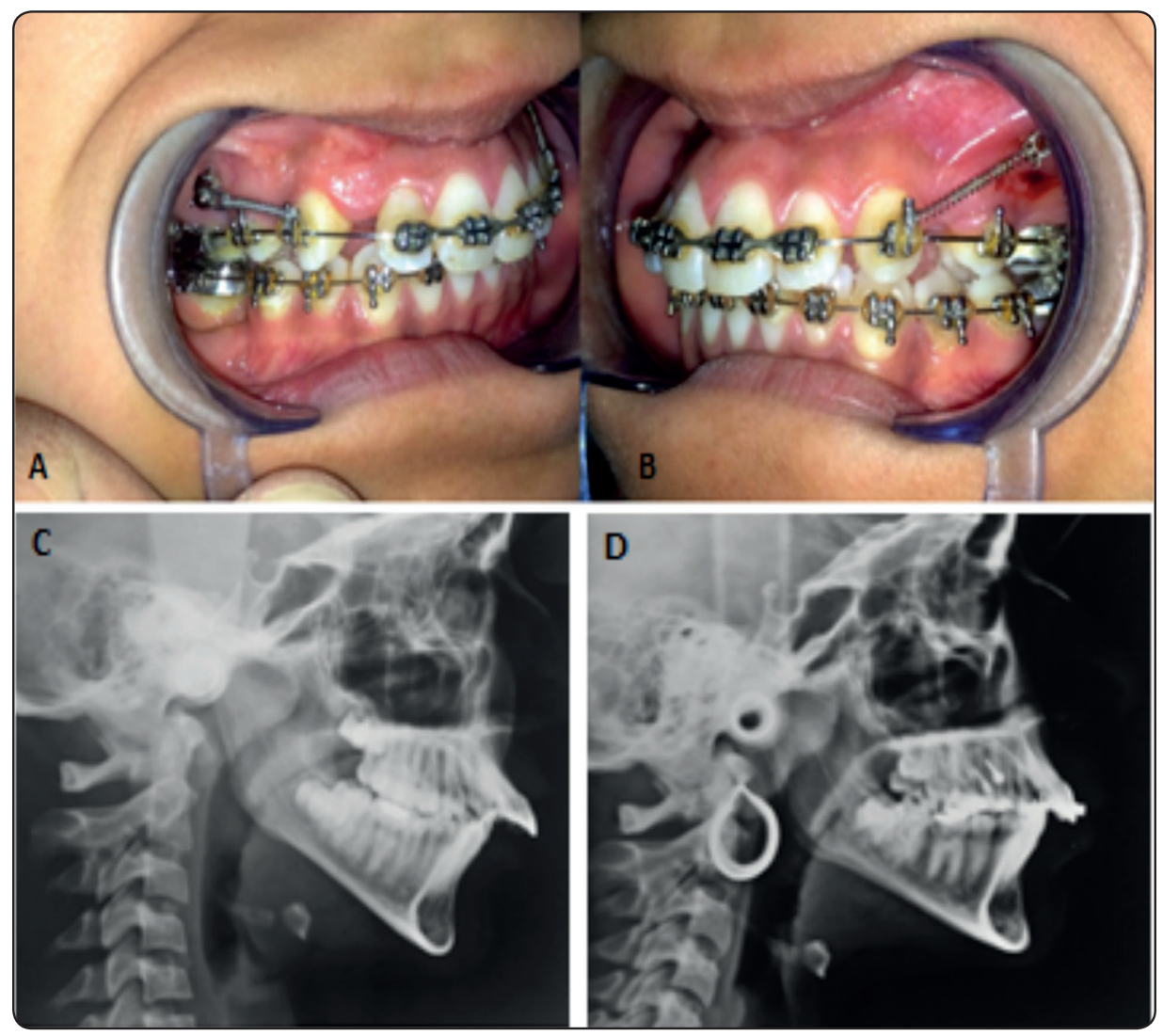

Fig. 3: (A) Intra-oral lateral view of a case reveal increased rate of canine retraction in corticotomy side, and decreased in control side (Fig. B), (C) Preoperative lateral cephalometric x ray (D) Postoperative lateral cephalometric x ray after 3 month.

TABLE (1) Comparison between measured parameters within groups

\begin{tabular}{|c|c|c|c|c|c|c|c|}
\hline \multirow{2}{*}{ Parameters } & \multirow{2}{*}{\multicolumn{2}{|c|}{ Groups }} & \multicolumn{2}{|c|}{ Corticotomy side } & \multicolumn{2}{|c|}{ Control side } & \multirow{2}{*}{ P-value } \\
\hline & & & Mean & $\mathrm{SD}$ & Mean & $\mathrm{SD}$ & \\
\hline \multirow{2}{*}{ Duration of canine retraction (days) } & \multicolumn{2}{|c|}{ Group I } & 136.9 & 2.6 & 152.1 & 2.9 & $<0.001^{* *}$ \\
\hline & \multicolumn{2}{|c|}{ Group II } & 120.4 & 2.9 & 150.9 & 2.5 & $<0.001 * *$ \\
\hline \multirow{6}{*}{ Rate of canine retraction (mm/30days) } & \multirow{3}{*}{ Group I } & $1 \mathrm{~m}$ & 1.73 & 0.04 & 0.80 & 0.03 & $<0.001 * *$ \\
\hline & & $2 \mathrm{~m}$ & 1.65 & 0.04 & 0.88 & 0.05 & $<0.001 * *$ \\
\hline & & $3 \mathrm{~m}$ & 1.19 & 0.08 & 0.96 & 0.03 & $<0.001 * *$ \\
\hline & \multirow{3}{*}{ Group II } & $1 \mathrm{~m}$ & 1.86 & 0.03 & 0.82 & 0.03 & $<0.001 * *$ \\
\hline & & $2 m$ & 1.79 & 0.04 & 0.89 & 0.03 & $<0.001^{* *}$ \\
\hline & & $3 \mathrm{~m}$ & 1.29 & 0.08 & 0.96 & 0.02 & $<0.001 * *$ \\
\hline \multirow{2}{*}{ Changes in Molar anchorage loss } & \multicolumn{2}{|c|}{ Group I } & 0.3 & 0.1 & 0.4 & 0.1 & 0.660 \\
\hline & \multicolumn{2}{|c|}{ Group II } & 0.2 & 0.1 & 0.3 & 0.1 & 0.593 \\
\hline \multirow{2}{*}{ Root resorption ( mm) } & \multicolumn{2}{|c|}{ Group I } & -0.3 & 0.1 & -0.3 & -0.4 & 0.915 \\
\hline & \multicolumn{2}{|c|}{ Group II } & -0.4 & 0.1 & -0.3 & 0.1 & 0.196 \\
\hline \multirow{2}{*}{ Changes in GI } & \multicolumn{2}{|c|}{ Group I } & 1.0 & 0.5 & 0.1 & 0.3 & 2410 \\
\hline & \multicolumn{2}{|c|}{ Group II } & 1.0 & 0.5 & 0.3 & 0.5 & 0.139 \\
\hline
\end{tabular}

* Significant at $P \leq 0.05$

** Highly significant $P \leq 0.001$ 
TABLE (2) Comparison between measured parameters of groups

\begin{tabular}{|c|c|c|c|c|c|c|}
\hline \multirow{2}{*}{\multicolumn{2}{|c|}{ Parameters }} & \multicolumn{2}{|c|}{ Group I } & \multicolumn{2}{|c|}{ Group II } & \multirow{2}{*}{ P-value } \\
\hline & & Mean & SD & Mean & SD & \\
\hline \multicolumn{2}{|l|}{ Duration of canine retraction (days) } & 136.9 & 2.6 & 120.4 & 2.9 & $<0.001 * *$ \\
\hline \multirow{3}{*}{ Rate of canine retraction ( $\mathrm{mm} / 30$ days) } & $1 \mathrm{~m}$ & 1.73 & 0.04 & 1.86 & 0.03 & $<0.001 * *$ \\
\hline & $2 \mathrm{~m}$ & 1.65 & 0.04 & 1.79 & 0.04 & $<0.001 * *$ \\
\hline & $3 m$ & 1.19 & 0.08 & 1.29 & 0.08 & $<0.001 * *$ \\
\hline \multicolumn{2}{|l|}{ Changes in Molar anchorage loss } & 0.3 & 0.1 & 0.3 & 0.1 & 0.580 \\
\hline \multicolumn{2}{|l|}{ Root resorption ( $\mathrm{mm}$ ) } & -0.3 & 0.1 & -0.4 & 0.1 & 0.563 \\
\hline \multicolumn{2}{|l|}{ Changes in GI } & 1.0 & 0.5 & 1.0 & 0.5 & 0.103 \\
\hline
\end{tabular}

* Significant at $P \leq 0.05 \quad * *$ Highly significant $P<0.001$

\section{DISCUSSION}

One of the main drawbacks of orthodontic treatment is long time. Protracted orthodontic treatment time has beenlinked to an increased risk of root resorption, gingival inflammation, decalcification, and dental caries ${ }^{(15,16)}$. To shorten orthodontic treatment time, various attempts have been devolped. These attempts included local or systemic administration of drugs ${ }^{(17,18)}$, mechanical or physical stimulation such as direct electrical current $^{(19)}$, and oral surgery, including dental distraction ${ }^{(20)}$,alveolar contouring ${ }^{(21)}$, and alveolar corticotomies $^{(2-5)}$, which have been utilized related to orthodontics to address malocclusions for over numerous years.

In this study, cortical vertical grooves, and a modified corticotomy (perforations and vertical grooves) were made in the buccal cortical plate of bone as it were. The principle motivations behind receiving this traditionalist strategy were to shorten operation time, postoperative patient discomfort and high risk of complications by eliminating an additional palatal surgery.

In this study, skeletal anchorage was performed using miniscrews implants during canine retraction.
They were placed in the attached gingiva instead of the non-keratinized mucosa since we expected that the achievement rates would be higher .All miniscrews demonstrated no looseness during canine retraction except for 4 miniscrews. Which were removed and reinserted after healing of the inflammation and canine retraction was resumed. These resultsdemonstrated that the success rate of miniscrews in this study was approximately $91.7 \%$, which is as per past reports ${ }^{(22,23)}$.

Current study has demonstrated that retraction of canines was significantly higher $(\mathrm{P} \leq 0.01)$ on the corticotomy side than on the control side in all groups during the 1st and 2nd months intervals. After the corticotomy surgery by two months, the average monthly rate of canine retraction was significantly higher $(\mathrm{P} \leq 0.01)$ around 1.8 times quicker on the corticotomy side contrasted andthe control side in all groups. During the $3^{\text {rd }}$ month, this mean monthly rate, howeverstill higher on the corticotomy than the control side, it declined to only 1.4 times higher in the third month. This findings are agree with those of Kevin et al, ${ }^{(24)}$ Liem et al ${ }^{(25)}$, and Farid et $\mathrm{al}^{(26)}$ who revealed that tooth movement speed on the corticotomy side was double to triple times quicker than that on the control side.. 
In this investigation evaluation of gingival index, and canine apical root resorption exhibited no significant contrasts between the corticotomy and control sides when canine retraction. These concurred with the discoveriesof Wilcko et al, (27) and Iino et al, ${ }^{(4)}$ who who revealed fast tooth movement and decreased treatment times without recognizable antagonistic periodontal effects from the corticotomy facilitated orthodontic.

In present investigation, the lingual vertical and supra-apical horizontal cuts were not performed and lingual flap was not raised, in order to support the blood supply of the dentoalveolar region by lingual mucosa, though the admittance to the lingual cortical bone was accomplished from the labial side. This is in accordance with Suryavanshi et al (2) study. However, this in opposite side with principles of conventional corticotomy technique.

Our results demonstrated that Corticotomy side in group I showed statistically significant longer canine movement duration than groups II although it showed statistically significant shorter duration than the control side. This is in the same sides of conclusions of Patterson et al ${ }^{(28)}$ review.

\section{CONCLUSION}

Corticotomy is an intrusive methodology, which lessens the resistance of bone during tooth movement, prompting shortening the time of orthodontic treatment. Modified corticotomy procedure is mix among vertical and hole corticotomy which fills in as a compelling method to quicken orthodontic tooth movement, without unfavorably influencing the periodontium, or root resorption.

\section{CONFLICTS OF INTEREST}

There are no conflicts of interest.

\section{Funding}

No funding

\section{REFERENCES}

1. Murphy KG, Wilcko MT, Wilcko WM, Ferguson DJ: Periodontal accelerated osteogenic orthodontics: a description of the surgical technique. J Oral Maxillofac Surg 2009, 67: 2160-6.

2. Suryavanshi HN, Das VR, Deshmukh A, Rai R, Vora M. Comparison of rate of maxillary canine movement with or without modified corticotomy facilitated orthodontic treatment: A prospective clinical trial. APOS Trends Orthod 2015;5:138-43.

3. Lee JK, Chung KR, Baek SH. Treatment outcomes of orthodontic treatment, corticotomy-assisted orthodontic treatment, and anterior segmental osteotomy for bimaxillary dentoalveolar protrusion. PlastReconstr Surg 2007; 120:1027-36.

4. Iino S, Sakoda S, Miyawaki S. An adult bimaxillary protrusion treated with corticotomy-facilitated orthodontics and titanium miniplates. Angle Orthod 2006;76:1074-82.

5. Moon CH, Wee JU, Lee HS. Intrusion of overerupted molars by corticotomy and orthodontic skeletal anchorage. Angle Orthod 2007;77:1119-25.

6. Spena R, Caiazzo A, Gracco A, Siciliani G. The use of segmental corticotomy to enhance molar distalization. J Clin Orthod 2007;41:693-9.

7. Akay MC, Aras A, Günbay T, Akyalçin S, Koyuncue BO. Enhanced effect of combined treatment with corticotomy and skeletal anchorage in open bite correction. J Oral Maxillofac Surg 2009;67:563-9.

8. Kanno T, Mitsugi M, Furuki Y, Kozato S, Ayasaka N, Mori H. Corticotomy and compression osteogenesis in the posterior maxilla for treating severe anterior open bite. Int $\mathbf{J}$ Oral Maxillofac Surg 2007;36:354-7.

9. Hassan AH, AlGhamdi AT, Al-Fraidi AA, Al-Hubail A, Hajrassy MK. Unilateral cross bite treated by corticotomy-assisted expansion: Two case reports. Head Face Med 2010;6:6-11.

10. Kuo PC. Maxillary expansion following modifi ed maxillary corticotomy - Its efficacy and long-term stability. J Oral Maxillofac Surg 1991;49 Suppl 1:93-4

11. Motohashi T, Nakajima M, Kakudo K. Biomechanical effects of orthodontic treatment by using anchorage device combined with corticotomy. J Craniomaxillofac Surg 2006;34 (Supp 1):208- 13. 
12. Kashkoul B, Hshma O, Sawan MN. Segmental corticotomy for retracting the anterior maxilla. J Craniomaxillofac Surg 2008;36 (Supp 1):103-8.

13. Gil APS, et al., Alveolar corticotomies for accelerated orthodontics: A systematic review, Journal of Cranio- Maxillo-Facial Surgery 2018, 1-8.

14. Germeç D, Giray B, Kocadereli I, Enacar A. Lower incisor retraction with a modifi ed corticotomy. Angle Orthod 2006;76:882-90.

15. Artun J, Brobakken BO. Prevalence of carious white spots after orthodontic treatment with multibonded appliances. Eur J Orthod 1986;8:229-34.

16. Kurol J, Owman-Moll P, Lundgren D. Time-related root resorption afterr application of a controlled continuous orthodontic force. Am J Orthod Dentofacial Orthop 1996;110:303-10

17. Lee WC. Experimental study of the effect of prostaglandin administration on tooth movement - with particular emphasis on the relationship to the method of PGE1 administration. Am J Orthod Dentofacial Orthop 1990; 98:231-41.

18. Collins MK, Sinclair PM. The local use of vitamin D to increase the rate of orthodontic tooth movement. Am J Orthod Dentofacial Orthop 1988;94:278-84

19. Davidovitch Z, Finkelson MD, Steigman S, Shanfeld JL, Montgomery PC, Korostoff E. Electric currents, bone remodeling, and orthodontic tooth movement. II. Increase in rate of tooth movement and periodontal cyclic nucleotide levels by combined force and electric current. Am J Orthod 1980;77:33-47.
20. Liou EJ, Huang CS. Rapid canine retraction through distraction of periodontal ligament. Am J Orthod Dentofacial Orthop 1998;114:372-82

21. Murphy CA, Chandhoke T, Kalajzic Z, et al. Effect of corticision and different force magnitudes on orthodontic tooth movement in a rat model. Am. J. Orthod. Dentofacial Orthop. 2014;146(1):55-66.

22. Bae SM, Park HS, Kyung HM, Kwon OH, Sung JH. Clinical application of micro-implant anchorage. J Clin Orthod 2002;34: 298-302.

23. Park HS, Jeong SH, Kwon OW. Factors affecting the clinical success of screw implants used as orthodontic anchorage. Am J Orthod Dentofacial Orthop 2006;130:18-25.

24. Kevin G. Murphy, M. Thomas Wilcko, William M. Wilcko Donald J. Ferguson. Periodontal Accelerated Osteogenic Orthodontics: A Description of the Surgical Technique. J Oral Maxillofac Surg 2009;67:2160-6.

25. Liem AM, Hoogeveen EJ, Jansma J, Ren Y. Surgically facilitated experimental movement of teeth: systematic review. Br J Oral Maxillofac Surg. 2015 Jul;53(6):491-506.

26. Farid KA, Mostafa YA, Kaddah MA, El-SharabyFA.Corticotomyfacilitated orthodontics using piezosurgery versus rotary instruments: an experimental study. J Int AcadPeriodontol. 2014 Oct;16(4):103-8.

27. Wilcko W, Wilcko MT. Accelerating tooth movement: The case for corticotomy-induced orthodontics. Am J Orthod Dentofacial Orthop 2013;144:4-12.

28. Patterson BM, Dalci O, Darendeliler MA, Papadopoulou AK. Corticotomies and orthodontic tooth movement: a systematic review. J Oral Maxillofac Surg 2016;74:453-73. 